\title{
Görüntü İşleme ve Robot Kol Tabanlı Çikolata Toplama ve Paketleme Sistemi
}

\author{
Muhammed Ali Y1lmaz ${ }^{*}$, Cemil Sungur ${ }^{2}$

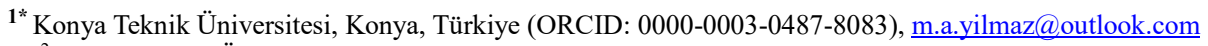 \\ ${ }^{2}$ Konya Teknik Üniversitesi, Konya, Türkiye (ORCID: 0000-0003-2340-6225), csungur@ktun.edu.tr
}

(2nd International Conference on Computer, Electrical and Electronic Sciences ICCEES 2021, September 1-3, 2021)

(DOI: $10.31590 /$ ejosat.1005485)

ATIF/REFERENCE: Yılmaz, M. A. \& Sungur, C. (2021). Görüntü İşleme ve Robot Kol Tabanlı Çikolata Toplama ve Paketleme Sistemi. Avrupa Bilim ve Teknoloji Dergisi, (30), 79-82.

\section{$\ddot{O} \mathbf{z}$}

$\mathrm{Bu}$ çalışmada bir konveyör bant üzerinden akan çikolatalar bir kamera yardımıyla toplanmıştır. Rastgele ve dağınık şekilde gelen çikolatalar konveyör bant üzerine yerleştirilmiş bir kamera ile tespit edilmiştir. Tespit edilen çikolataların merkez koordinatları robot kola gönderilmiştir. Robot kol gelen çikolata koordinatları ile konveyör banta bağlı enkoder bilgisini kullanarak sistemi durdurmadan çikolata toplama ve paketleme işlemini gerçekleştirmiştir. Görüntü işleme aşamasında HSV dönüşümü, kenar tespiti ve moment yöntemleri kullanılarak çikolatalar yüksek doğrulukla tespit edilmiştir. Kamera - robot kol birbirine kalibre edilerek toplama işlemini hatasız yapan bir otomasyon sistemi kurulmuştur. Görüntü işleme donanımı olarak bilgisayar kullanılmıştır. Bilgisayar-robot kol arasındaki haberleşme işlemi Modbus TCP/IP yöntemi ile yüksek hızda gerçekleştirilmiştir.

\section{Chocolate Picking and Packaging System with Robotic Arm based on Image Processing}

\begin{abstract}
In this study, chocolates flowing over a conveyor belt were collected with the help of a camera. Random and scattered chocolates were detected with a camera placed on the conveyor belt. The center coordinates of the detected chocolates were sent to the robot arm. The robot arm carried out the chocolate collection and packaging process without stopping the system by using the incoming chocolate coordinates and the encoder information connected to the conveyor belt. Chocolates were detected with high accuracy by using HSV transform, edge detection and moment methods in the image processing stage. An automation system has been established that makes the collection process error-free by calibrating the camera and robot arm to each other. Computer was used as image processing hardware. The communication process between the computer and the robot arm was carried out at high speed using the Modbus TCP/IP method.
\end{abstract}

Keywords: Automation system, chocolate picking, Image processing, Robotic Arm, OpenCV.

\footnotetext{
*Sorumlu Yazar: baysal.selimsefa@aydtr.com
} 


\section{Giriş}

Endüstride seri üretimde ürün toplama ve paketleme işlemleri genel olarak insanlar ile yapılır. İnsan çalışan sistemlerde verim sürekli yüksek olmamakla birlikte insanın hata yapma olasılığ yüksektir. Bu nedenle seri üretimler için bir otomatik toplama ve paketleme sistemi gereklidir. Endüstri 4.0 bilişim ve endüstri faaliyetlerinin ortak çalışması olarak açıklanmakta olup son zamanlarda popüler olmuş bir terimdir. Bilişim teknolojilerine de görüntü işleme, makine öğrenmesi ve yapay zekâ liderlik etmektedir. Yapay zekâ ile makineler daha "akıllı" bir hale getirilerek üretim sistemleri değiştirilmektedir. İnsansı işleri yapan robotlar, akıllı bilgisayarlar ve gelişmiş otomasyon sistemleri günümüzde normal karşılanmaya başlamıştır. Teknolojinin yakaladığı yükselişin etkisi bunun en büyük sebeplerinden birisidir. Fabrikalarda yer alan akıllı otomasyon sistemleri, yine fabrikalarda insana özgü görevleri yapan ve birbirleriyle etkileşime geçen akıllı robotlar teknolojinin ilerlemesini sağlamaktadır.

Yundong Li ve ark. [1] gerçekleştirdikleri çalışmada deforme olmuş desenli kumaşları Fisher Kriter Tabanlı Derin Öğrenme (FKTDÖ) yöntemiyle tespit etmiştir. İlk olarak, kumaş görüntüleri aynı boyuttaki parçalara bölünmüş ve FKTDÖ sistemi eğitilmiştir. İkinci aşamada FKTDÖ aracılığıyla kusurlu ve sağlam şeklinde sınıflandırılmıştır. Son olarak, yeniden yapılandırılmış görüntü ile arızalı arasında kalan görüntüler hesaplanır ve kusur işlemi eşikleme yöntemi ile bulunmuştur. Deneysel sonuçlar önerilen yöntemin etkinliğini göstermiş ve kumaşları hatasız ve kusurlu olmak üzere başarılı bir şekilde sınıflandırmışlardır. Hussam Elbehiery ve ark. [2] görüntü işleme yöntemlerini kullanarak seramik karo imalatında kalite kontrol işlemi gerçekleştirmiştir. Homojenliği iyileştirmek için paketleme işleminden önce histogram eşitleme, kenar tespiti gürültü giderme, boşlukları doldurma tekniklerini kullanarak seramik karolarda renk analizi, boyut doğrulama ve yüzey kusur tespiti yapmışlardır. Görüntü işleme yöntemlerinden elde edilen sonuçlar kullanılarak ürün kalitesi ve üretim verimliliği konularında çalışmalar yapılmaya başlanmıştır. Özdemir ve ark. [3] akıllı fabrika prototipinde Derin Öğrenme yöntemi ile kalite kontrol uygulaması yapmışlardır. Çalışmada akıllı fabrika modelinde montaj hattına koyulan bir kamera ile görsel kalite kontrol otomasyonu önerilmiştir. Önerilen yöntemde kameradan elde edilen görüntü MATLAB ortamında işlenmiştir. İşlem sonucunda ürün üretim bandından ayrılmış veya bantta işlenmeye devam etmiştir. JavierVillalba-Diez ve ark. [4] baskı endüstrisinde derin öğrenme yöntemleriyle kalite kontrol çalışması yapmışlardır. Gravür silindirlerinin üretim aşamasında oluşan hataları Derin Sinir Ağı (DNN) ile en aza indirmek üzere çalışmıştır. Yüksek çözünürlüklü optik kalite kontrol kamerası yardımıyla yapılan bu çalışmada \%98,4 lük bir doğruluk oranı yakalamışlardır. Korkmaz ve Barstuğan [5] robot kolunun ucuna monte edilen bir kamera ile konveyör bant üzerinden akan frekans inverterlerinin kalite kontrolünü yapmıștır. Çalışmalarında ilk olarak inverter tespit edilmiş, daha sonra konveyör bant durdurulmuştur. Bant durduktan sonra robot kol otomatik olarak frekans inverterinin kalite kontrolünün yapılacağı konuma gitmiştir. Kalite kontrol noktasında frekans inverterine frenleme direncinin takılıp takılmadığı tespit edilmiştir. Tespit işleminde kameradan alınan görüntü sınıflandırılmış ve sınıflandırma sonucuna göre bir karar verilmiştir.

\section{Materyal ve Metot}

Bu çalışma, Konya Teknik Üniversitesi Mühendislik ve Doğa Bilimleri Fakültesi Elektrik-Elektronik Mühendisliği Bölümü Endüstriyel Otomasyon Laboratuvarı'nda gerçekleştirilmiştir. Çalışmada Logitech C270 kamera ile görüntüleme işlemi yapılmıştır. Elde edilen görüntüler Python ortamında OpenCV kütüphanesi ile işlenmiş, konveyör sistemi ve robot kolu kontrol etmek için Mitsubishi FX5U PLC kullanılmıştır. PLC ve Python yazılım dili MODBUS TCP/IP haberleşmesi üzerinden haberleştirilmiştir. Kurulan sistemin yapısı Şekil 1'de görülmektedir.

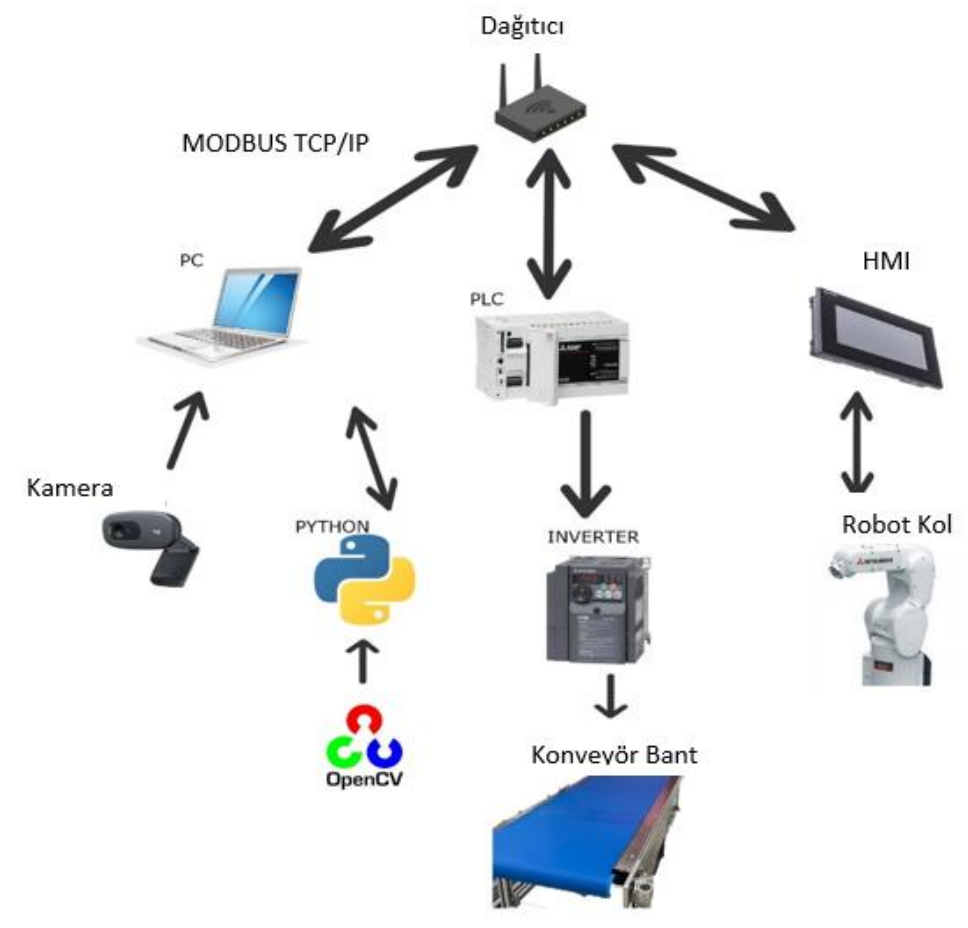

Şekil 1. Kurulan sistem ve haberleşme yapısı 


\subsection{Görüntü İşleme}

Görüntü işleme aşamasında HSV dönüşümü, kenar tespiti ve moment bulma yöntemleri kullanılmıştır.

\section{$>$ HSV dönüşümü}

Kameradan alınan görüntüde renkler üzerinden daha kolay işlem yapabilmek için BGR (Blue Green Red) renk uzayından HSV (Hue Saturation Value) renk uzayına geçiş yapılmıştır. HSV renk uzayı sırasıyla renk özü, doygunluk ve parlaklık terimlerini ifade eder. Renk özü, rengin baskın dalga uzunluğunu belirler. Doygunluk, rengin canlılı̆̆ını belirler. Parlaklık ise rengin aydınlığın yani beyaz oranını belirler. Şekil 2'de HSV renk uzayının gösterimine yer verilmiştir.

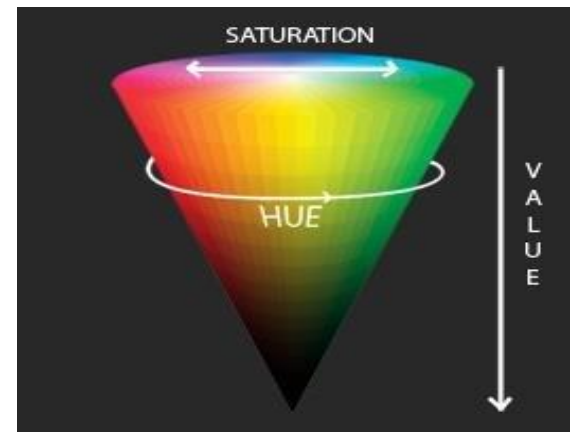

Şekil 2. HSV renk uzayı

\section{$>$ Kenar tespiti}

Kenarlar, aynı renge ve yoğunluğa sahip tüm sürekli noktaları (sınır boyunca) birleştiren bir eğri olarak açıklanabilir [6]. Bir görüntünün kenarlarını bulmak, görüntüdeki önemli yapısal özellikleri korurken verinin büyük bir kısmını önemli ölçüde azaltır ve gereksiz bilgiyi filtreler. Kenar tespiti, şekil analizi ve nesne tanıma-algılama için kullanışlı bir araçtır. Şekil 3 'te basit bir dikey kenar bulma yönteminin matris olarak gösterimi görülmektedir.
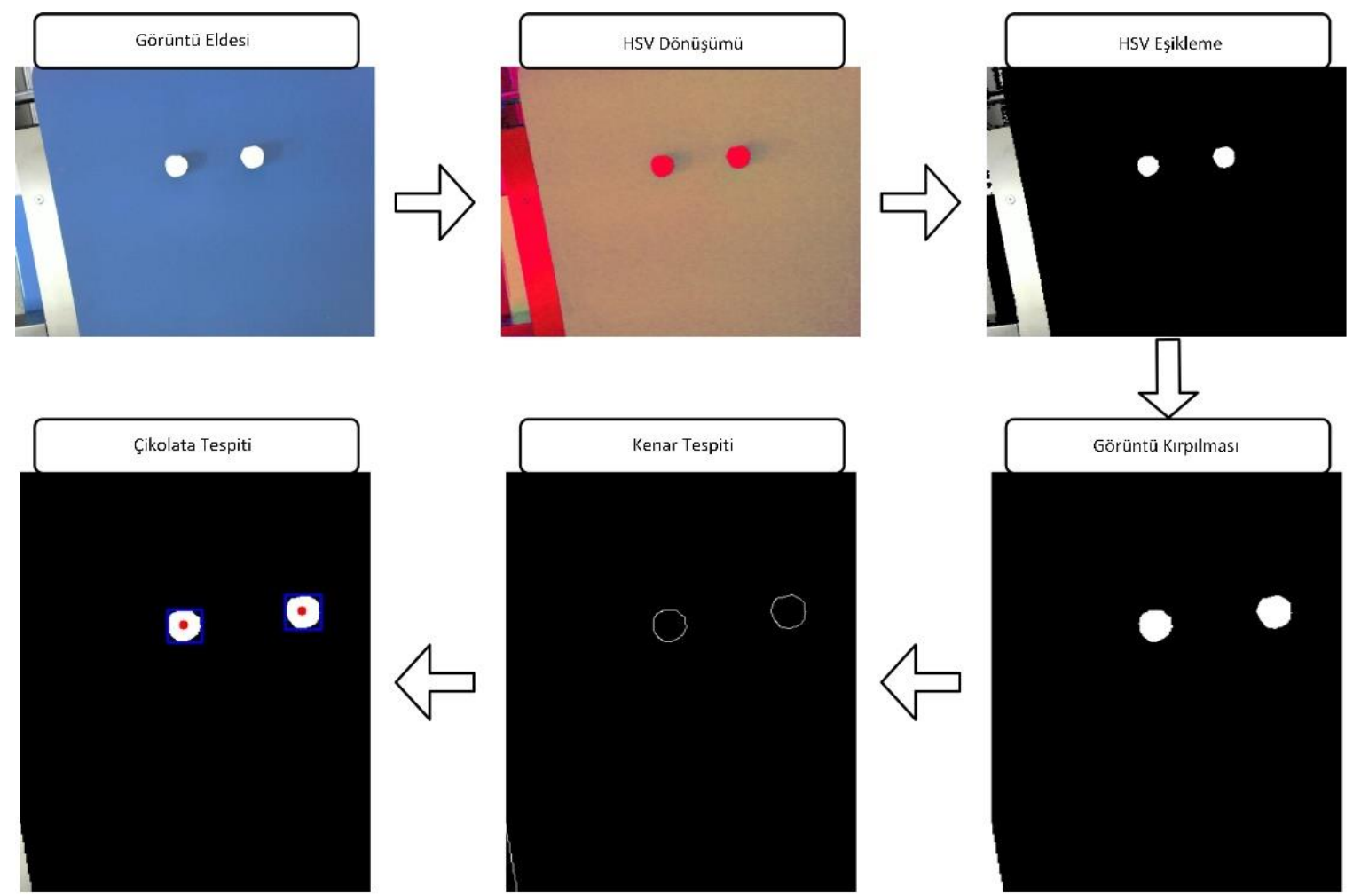

\section{Araștırma Sonuçları ve Tartıșma}

$\mathrm{Bu}$ çalışmada uygulanan görüntü işleme metotları ve elde edilen sonuçlar Şekil 4'te sunulmuştur. Kameradan elde edilen görüntü öncelikle HSV dönüşümü işlemi uygulanmış, daha HSV görüntü eşiklenmiştir. Eşiklenen görüntü üzerinde kenar tespiti yapılarak çikolatalar tespit edilmiştir. Elde edilen çikolataların merkez konumları momentleri alınarak hesaplanmıştır.
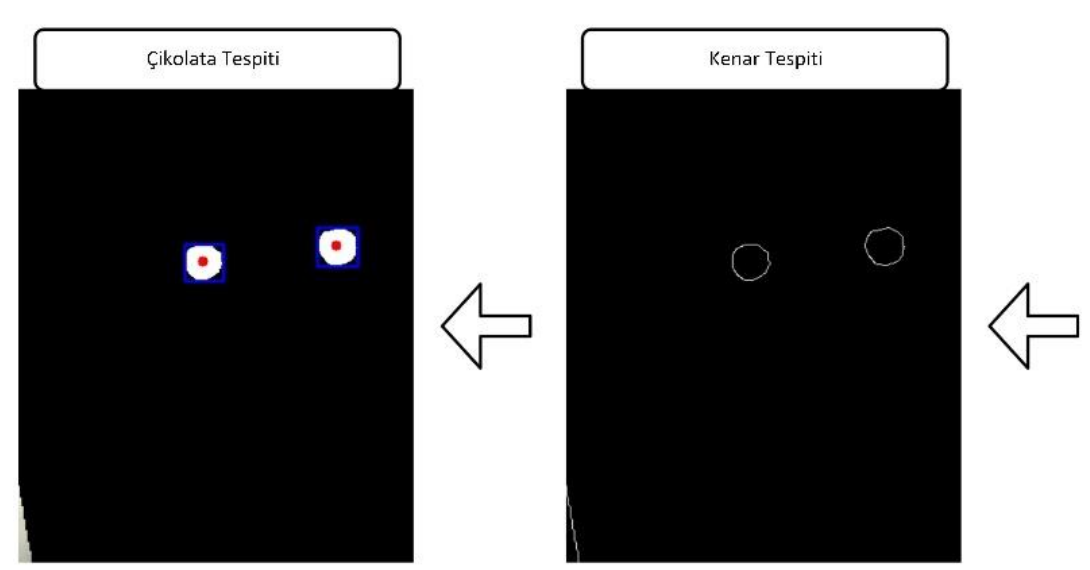

Şekil 4. Önerilen yöntem ve görsel sonuçlar 


\section{Sonuç}

Görüntü işleme teknikleri fabrika ortamlarında kullanılmaya uygun ve yüksek performanslı sonuçlar veren yöntemlerdir. Bu sayede fabrika ortamında insan etkisi ortadan kaldırılarak yüksek verimle çalışabilen sistemler ortaya konulabilmektedir. Elde edilen sonuçlar robot kolun kameradan gelen çikolata konumlarına yüksek doğrulukla giderek çikolataları toplayabildiğini göstermektedir.

\section{Teșekkür}

Bölümümüz laboratuvarında kullanılan otomasyon ürünlerini hibe eden Mitsubishi Electric firmasına, konveyör sistemini hibe eden MEMAK Makine firmasına teşekkür ederiz.

\section{Kaynakça}

[1] Li, Y., Zhao, W., \& Pan, J. (2016). Deformable patterned fabric defect detection with fisher criterion-based deep learning. IEEE Transactions on Automation Science and Engineering, 14(2), 1256-1264.

[2] Elbehiery, H., Hefnawy, A., \& Elewa, M. (2005). Surface defects detection for ceramic tiles using image processing and morphological techniques.

[3] Ozdemir, R., \& Koc, M. (2019, September). A quality control application on a smart factory prototype using deep learning methods. In 2019 IEEE 14th International Conference on Computer Sciences and Information Technologies (CSIT) (Vol. 1, pp. 46-49). IEEE.

[4] Villalba-Diez, J., Schmidt, D., Gevers, R., Ordieres-Meré, J., Buchwitz, M., \& Wellbrock, W. (2019). Deep learning for industrial computer vision quality control in the printing industry 4.0. Sensors, 19(18), 3987.

[5] Korkmaz, M., \& Barstuğan, M. (2020). A Deep LearningBased Quality Control Application. Avrupa Bilim ve Teknoloji Dergisi, 332-336.

[6] Ozkava, U., Ozturk, S., Akdemir, B., \& Sevfi, L. (2018, October). An efficient retinal blood vessel segmentation using morphological operations. In 2018 2nd International Symposium on Multidisciplinary Studies and Innovative Technologies (ISMSIT) (pp. 1-7). IEEE. 